\title{
Integration of multi-classifiers in object-based methods for forest classification in the Loess plateau, China
}

\author{
Pengxiang Zhao ${ }^{\mathrm{a}}$, Jun Zhao ${ }^{\mathrm{a}, *}$, Jianghua $\mathrm{Wu}^{\mathrm{b}}$, Yanzheng Yang ${ }^{\mathrm{a}, \mathrm{c}}$, Wei Xue ${ }^{\mathrm{a}}$, Yichen $\mathrm{Hou}^{\mathrm{a}}$ \\ a College of Forestry, Northwest A\&F University, Taicheng 3 Road, Yangling 712100 China \\ b Sustainable Resource Management, Grenfell Campus, Memorial University of Newfoundland, \\ Corner Brook, NL, A2H6P9 Canada \\ c Centre for Earth System Science, Tsinghua University, 100084, Beijing, China
}

*Corresponding author, e-mail: zhaojun148@126.com

Received 22 Nov 2014

Accepted 1 Jul 2016

\begin{abstract}
The object-oriented method with three integrated different classifiers was applied to classify satellite images of the forest in the Loess Plateau in China. After image segmentation, feature selection, and training sample selection, three classifiers-the support vector machine (SVM), $k$-nearest neighbour algorithm, and classification and regression tree-were used for forest classification using SPOT images as the data source. Results indicated that the object-oriented method with the three classifiers effectively extracted Chinese pine forestland, Betula forestland, oak forestland, shrubland, wasteland, farmland, and roads in the study area. The main segmentation parameters of scale, colour, and shape performed best when their values were set to $100,0.9,0.1$ in forestland and $60,0.5,0.5$ in nonforestland, respectively. In addition, SVM was the best classifier applied to the forest classification with an overall accuracy of $78 \%$ and a kappa coefficient of 0.737 . This study provides a fast and flexible approach to forest classification and lays the foundation for forest management and forest resource surveys.
\end{abstract}

KEYWORDS: object-based classification, image segmentation, feature selection, remote sensing

\section{INTRODUCTION}

The vegetative land cover is an important variable in earth-system processes ${ }^{1}$. Forests serve a crucial function in protecting natural resources for humans and other life forms, in minimizing ecological and environmental deterioration, and in responding to the challenge of climate change ${ }^{2}$. Forest surveys provide the theoretical basis and technical support for analysing the status and dynamics of forest resources. They also have an important role in forecasting the change trend of forest resources and in formulating sustainable forest management plans ${ }^{3}$. The ability of China to manage its forest resources in a sustainable manner is challenging. In view of the advancement in the social economy, the conventional method for forest resource surveys in the country remains inherently limited and therefore fails to meet the requirements of the development of modern forestry. Remote sensing classification is one of the indispensable components of forest resource surveys, and its classification accuracy directly influences the level of applicability and practical value of such surveys. Thus improving the precision of classification is an urgent issue in the research field ${ }^{4,5}$.

The Loess Plateau is well known for its great development potential, but the area also suffers from the highest rates of erosion in the country and is the source of most of the deposited sediments in the Yellow River ${ }^{6,7}$. The change in land use and land cover in this region is significant and has a great effect on the local environment and diversity of the ecosystem ${ }^{8,9}$. Over the last decade, various approaches have been applied in classifying the land cover of the plateau; these approaches include unsupervised classification, supervised classification, and the genetic algorithm-based decision tree classifier ${ }^{6,10}$. At present, only a few studies have employed the object-oriented method in classifying the remote sensing images of the forest in the Loess Plateau.

The object-based classification is widely employed in land survey and monitoring and generates many good results ${ }^{11,12}$. It is however rarely employed in research on forest classification. The object-based technique takes groups of pixels or 'objects' instead of individual pixels as the unit of 
classification, and assigns every object in an image to a class ${ }^{13}$. Two basic methods can be employed for object-based classification: classification by rules and classification by training samples. In classification by rules, a classification tree based on binary recursive splitting was first developed, after which the data were divided into homogeneous groups ${ }^{14}$. This method is always time consuming because of repeated trials, and the rules built in one place cannot be applied in another place. In classification by training samples, stable training areas are chosen based on the experience of experts, after which a professional software is used to automatically classify the data into different classes. This process saves much time in building rules, thereby improving the efficiency and productivity of the method. The present study employs both methods for objectbased classification.

This study presents the parameters to be used in object-based classification and evaluates the performance of the method in the forest classification of the Loess Plateau. Three classifiers are also compared with each other to select the best one in the forest classification of the study area.

\section{MATERIALS AND METHODS}

\section{Study area}

The Caijiachuan forest farm (latitude: $35^{\circ} 28^{\prime}$ to $36^{\circ} 02^{\prime} \mathrm{N}$, longitude: $109^{\circ} 48^{\prime}$ to $110^{\circ} 12^{\prime} \mathrm{E}$ ) is located in the middle of Loess Plateau, China. Caijiachuan has an area of 20726 ha and is mostly between 1100 and $1300 \mathrm{~m}$ in altitude. The region has a semi-humid continental climate, with a mean annual precipitation of approximately $611 \mathrm{~mm}$ and a mean monthly temperature ranging from $21.8^{\circ} \mathrm{C}$ in July to $-5^{\circ} \mathrm{C}$ in January. The soil type in this region is cinnamon and grey cinnamon soil. This region is a typical forest of the Loess Plateau and is suitable for the study of the classification of forestland by remote sensing. This area is rich in forest resources, and the dominant species include Pinus tabulaeformis Carr., Betula platyphylla Suk., and Quercus wutaishanica Mayr. The location of the study area is shown in Fig. 1.

\section{Data sources and pre-processing}

Four data sets were employed for the classification of the Caijiachuan forest farm. The main image, 'Satellite Pour l'Observation de la Terre' (SPOT 5) high-resolution geometric (HRG) had a resolution of $10 \mathrm{~m}$ in the multi-spectral bands and $2.5 \mathrm{~m}$ in the panchromatic band. It was purchased from

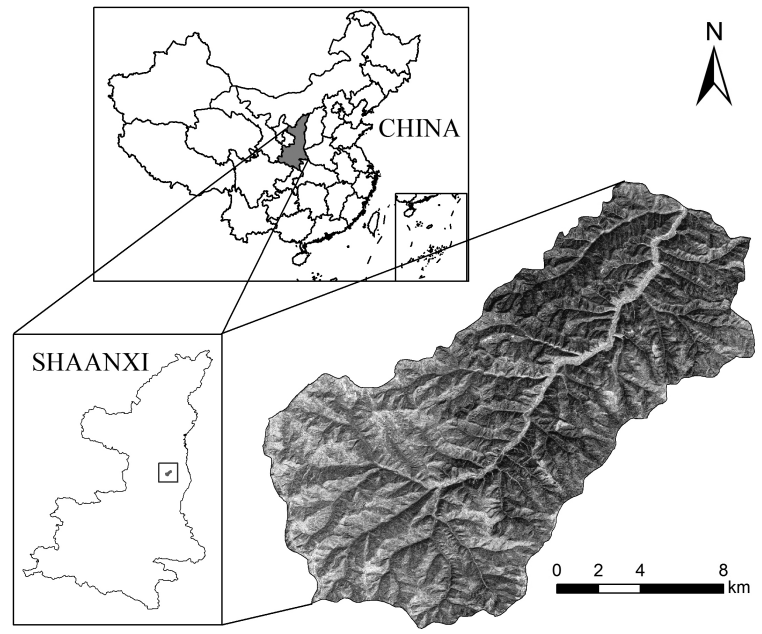

Fig. 1 Location of the study area.

Satellite Imaging Corp. (www.satimagingcorp.com) and was acquired on 18 September 2006. The advanced space borne thermal emission and reflection radiometer (ASTER) global digital elevation model data with a spatial resolution of $30 \mathrm{~m}$ were downloaded from website of Geospatial Data Cloud (www.giscloud.cn). The results of the forest resource survey in 2006 were also used to select the training area and to assess the classification results. The normalized difference vegetation index (NDVI) was derived from the SPOT 5 images and applied in the image segmentation.

Before implementing object-based classification, pre-processing procedures were applied for image enhancement to improve the results of image classification. The pre-processing procedures included radiometric correction, geometric correction, and resolution fusion. The enhanced image was then used in object-based classification. A flowchart of the sequence of operations is shown in Fig. 2.

\section{Image segmentation}

Image segmentation is a technique similar to computer vision and pattern recognition. This technique initially considers each pixel as an individual object, after which it merges the pixel with a neighbouring pixel with similar features, thereby producing a larger object than the original pixel. This process is repeated until the size of the objects meets the userspecified threshold ${ }^{15,16}$. The object-based classification software used in this study was ECOGNITION ProfessionAL 8.6.4. The multi-resolution segmentation approach is a bottom-up region-merging tech- 


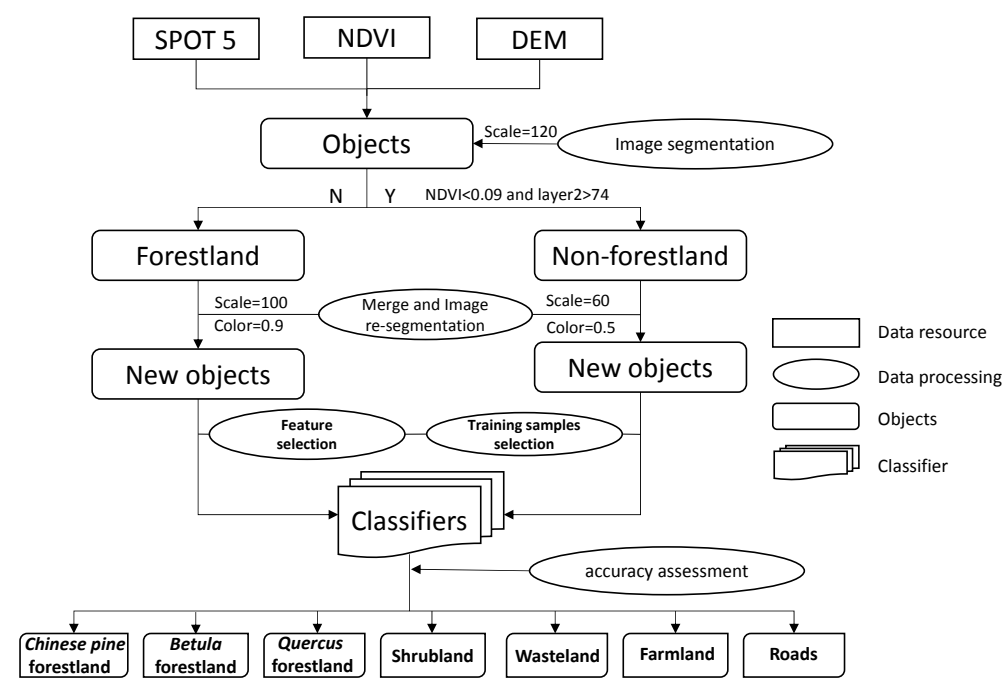

Fig. 2 Flowchart of the sequence of operations.

nique that starts with a one-pixel object ${ }^{17,18}$. As one of the latest and most suitable techniques in image segmentation ${ }^{19}$, the multi-resolution method was adopted to divide the whole area into different objects. Multi-resolution segmentation is based on four criteria: scale, colour, smoothness, and compactness ${ }^{17}$. Scale is the most important parameter and it affects the size of the objects and the border in the output classification map ${ }^{20}$. All four criteria must be optimized to obtain the best segmentation objects and to appropriately delineate the truth objects through repeated trials ${ }^{21,22}$.

In image segmentation, proper layers should be selected, and their importance degree must also be specified to estimate the spectral heterogeneity ${ }^{20}$. The heterogeneity $(f)$ of every object is determined by the object shape and colour:

$$
\begin{aligned}
f & =w h_{\text {colour }}+(1-w) h_{\text {shape }} \\
h_{\text {shape }} & =w^{\prime} h_{\text {compact }}+\left(1-w^{\prime}\right) h_{\text {smooth }}
\end{aligned}
$$

where $h_{\text {colour }}$ is the spectral heterogeneity; $h_{\text {shape }}$ is the heterogeneity of the shape; $h_{\text {compact }}$ is the compactness of the shape; and $h_{\text {smooth }}$ is the smoothness of the shape. The heterogeneity of the shape is determined by the smoothness and compactness of the shape, as shown in (2). In (1) and (2), $w$ (or $\left.w^{\prime}\right)$ is a weight ranging from $0-1$ and is used to describe the importance of the relative variable to the results. The larger the value of $w$ (or $w^{\prime}$ ) is, the higher the importance of the variable, and vice versa. The image segmentation process in this study was divided into three steps:

(i) A large scale (120) was applied in the first image segmentation, and the pixels were merged into different objects.

(ii) The objects were then divided into forestland and non-forestland based on the classification rules. The logical expression model developed for the classification of forestland and nonforestland was as follows.

If $($ NDVI $<0.09)$ or (layer $2>74)$,
then class = forestland;
otherwise, class = non-forestland.

otherwise, class = non-forestland. age. After examining the attributes of every object (i.e., either forestland or non-forestland), the neighbouring objects with similar attributes were merged into a larger object, which was then considered the mother-object of the second segmentation.

(iii) The second segmentation was processed based on the objects obtained in Step (ii).

Different parameters were employed for the various composition and structures of forestland and nonforestland. A smaller scale than that in the first segmentation was adopted in the second segmentation to delineate the forest vegetation polygons well (Table 1).

Table 1 Parameters of image segmentation based on objects.

\begin{tabular}{lcc}
\hline Segmentation parameters & Forestland & Non-forestland \\
\hline Scale & 100 & 60 \\
Colour & 0.9 & 0.5 \\
Shape(compact/smooth) & $0.1(0.5 / 0.5)$ & $0.5(0.5 / 0.5)$ \\
\hline
\end{tabular}


Table 2 List of object features.

\begin{tabular}{llc}
\hline Feature category & Object features & Number of features \\
\hline Spectral & Mean & 5 \\
& SD & 5 \\
Shape & Brightness & 1 \\
& Max-Diff & 1 \\
Texture & Length/width & 1 \\
& Shape index & 1 \\
& Homogeneity & 5 \\
& Contrast & 5 \\
& Dissimilarity & 5 \\
& Entropy & 5 \\
& ASM & 5 \\
& Mean & 5 \\
& SD & 5 \\
& Correlation & 5 \\
Total & Entropy & 5 \\
\hline
\end{tabular}

$\dagger$ The number of features was calculated using the four bands of SPOT 5 HRG after image confusion and one band of NDVI. The weight ratio of these five bands was 1:1:1:1:2. For brightness and max-diff, all the five bands were used; thus they have only one feature. Length/width and shape indices were calculated according to the shape of each object; thus they also have only one feature.

\section{Feature selection}

Much information is contained in the relationship between adjacent pixels as opposed to that in a single pixel; such information includes texture and shape, which are the key features of objects ${ }^{23}$. Feature selection chooses the suitable features (e.g., spectral, shape, and texture) that are used in objectbased classification. Texture is a vital parameter in object-based classification ${ }^{16}$. The grey level cooccurrence matrix (GLCM) was computed for every object. GLCM describes the co-occurrences of the pixel values that are separated at a distance of one pixel inside the polygon by considering the combined values of four different orientations ${ }^{24}$. All the object features selected in this study are described in Table 2.

\section{Training sample selection}

The training samples of seven land use types, including Chinese pine forestland, Betula forestland, Quercus forestland, shrubland, wasteland, farmland and roads, were selected from the segmentation objects for training classifiers. The forest survey data in 2006 was used as reference in selecting the training samples. The training samples were equally distributed and saved as stand ESRI shape file format.

\section{Classification using multi-classifiers}

After feature space selection and training sample selection, classification was performed with multiclassifiers. The three most commonly used classifiers, $k$-nearest neighbour (KNN), support vector machine (SVM), and classification and regression tree (CART), were selected in our study.

The KNN classifier, which is also called the nearest neighbour classifier, initially calculates the average vector and the standard deviation vector of each sample and then calculates the distance of the object and the sample. A short distance means a high similarity and categorization in the type with minimum distance. However, the KNN classifier increases the classification error rate when the training samples are unevenly distributed ${ }^{25}$. The SVM classifier is a new learning method based on spatial statistics, which can solve small sample problems and has good generalization ability using the principles of structural risk minimization. The SVM locates a hyperplane to correctly separate the data. More details on SVM classifier theory can be found in previous studies ${ }^{26,27}$. The present study uses the classification based on the SVM algorithm with the radial basis function kernel and disregards other kernels. The recursion algorithm for bisection is used in CART. This algorithm divides the current data set into two parts, and every non-leaf node has two branches in the decision tree, which is a binary tree with a terse structure ${ }^{28,29}$.

\section{RESULTS AND DISCUSSION}

\section{Image segmentation}

After the object was classified into either forestland or non-forestland, a small scale (60) was employed in the second segmentation for non-forestland objects in repeated trials because the scale showed an increase in landscape fragmentation. Forestland is the main landscape of the study area, and the segmentation scale (100) is $1 / 2$ to $2 / 3$ of the forest sub compartment. Shape and colour determine the heterogeneity of the object, and forestland and nonforestland should be given different weight values of colour and shape, respectively. The results of the image segmentation are shown in Fig. 3. 


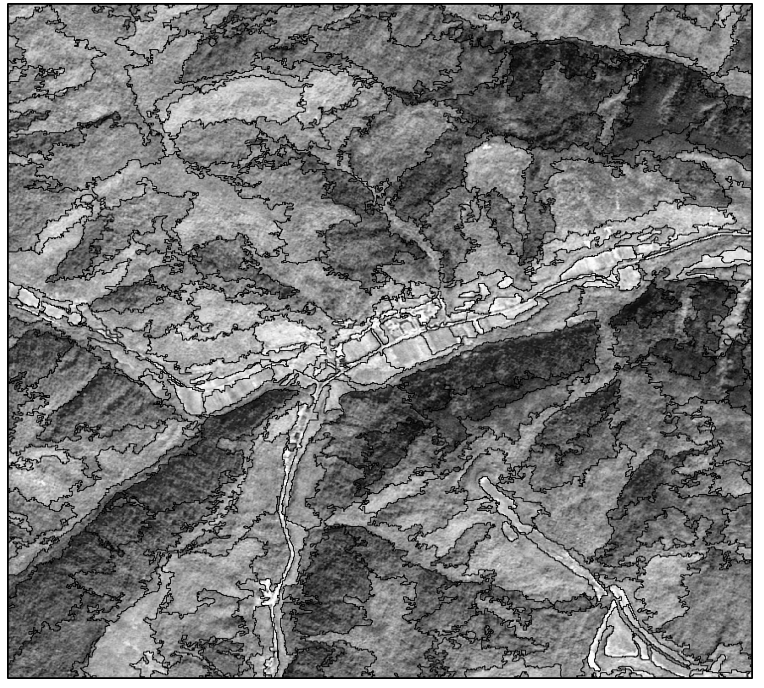

Fig. 3 Image segmentation.

\section{Image classification and accuracy assessment}

The classification results were obtained through the three classifiers with similar training samples. A comparison of the results showed that SVM was the best classifier with the most accurate result. The classification results of the three classifiers are shown in Fig. 4. To assess the classification results, a total of 243 objects were selected from the study area, see Table 3 . These objects were distributed equally and were proportional to the total area of these types. The overall accuracy and kappa coefficient were used to assess the accuracy of the three classifications. The results were illustrated with comparison of the three classifiers. SVM was found to be the most accurate classifier with a total accuracy of $78 \%$ and kappa coefficient of 0.737 , followed by KNN with a total accuracy of $74 \%$ and kappa coefficient of 0.712 . CART was the least accurate classifier with a total accuracy of $65 \%$ and
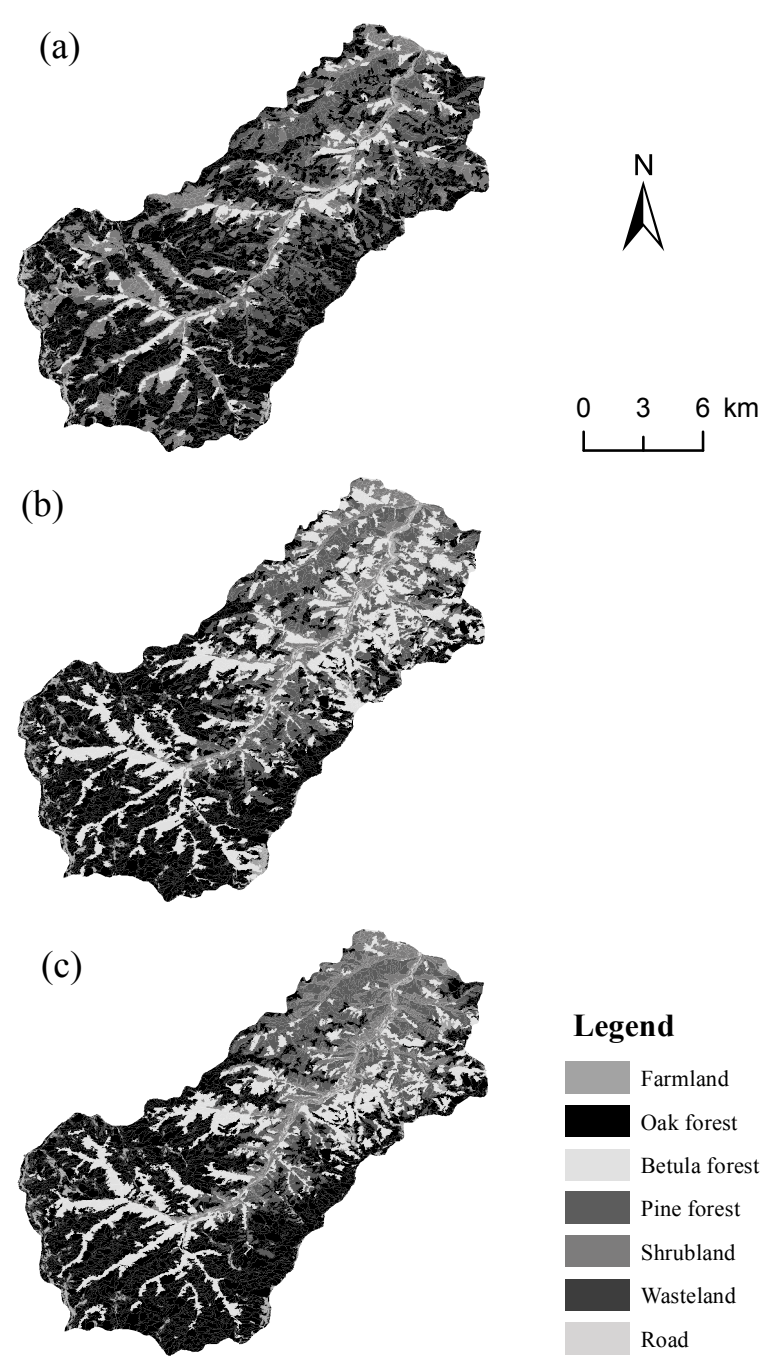

Fig. 4 Comparison of the results of the three classifiers. (a) CART; (b) KNN; (c) SVM.

kappa coefficient of 0.673 .

In conclusion, the order of the three classifiers in terms of accuracy is SVM $>$ KNN $>$ CART. The

Table 3 Confusion matrix of the results of the SVM classifier.

\begin{tabular}{|c|c|c|c|c|c|c|c|c|c|}
\hline Types & Chinese pine & Betula & Quercus & Shrubland & Wasteland & Farmland & Roads & Total & Accuracy \\
\hline Chinese pine forest & 40 & 3 & 5 & 2 & 1 & 0 & 0 & 51 & $78 \%$ \\
\hline Betula forest & 3 & 35 & 4 & 3 & 0 & 1 & 0 & 46 & $76 \%$ \\
\hline Quercus forest & 7 & 3 & 48 & 1 & 1 & 0 & 0 & 60 & $80 \%$ \\
\hline Shrubs & 1 & 1 & 2 & 18 & 1 & 1 & 0 & 24 & $75 \%$ \\
\hline Wasteland & 1 & 0 & 1 & 0 & 15 & 1 & 0 & 18 & $83 \%$ \\
\hline Farmland & 0 & 1 & 1 & 1 & 2 & 16 & 1 & 22 & $73 \%$ \\
\hline Road & 0 & 0 & 0 & 1 & 1 & 2 & 18 & 22 & $82 \%$ \\
\hline Total $^{\dagger}$ & 52 & 43 & 61 & 26 & 21 & 21 & 19 & 243 & $78 \%$ \\
\hline
\end{tabular}

\footnotetext{
$\dagger$ Total accuracy $=(40+35+48+18+15+16+18) / 243=78 \%$, kappa coefficient $=0.737$.
} 
results showed that the SVM classifier was more effective than the two other classifiers (KNN and CART). However, SVM also had disadvantages in terms of sensitivity to the Hughes phenomenon ${ }^{26}$, which is common in processing widely used hyperspectral images.

\section{CONCLUSIONS}

This study focused on each of the processes of object-based classification, including determining the optimum segmentation scale and weight ratio of every band and selecting the feature space and classifiers. The study area was divided into seven types: Chinese pine forestland, Betula forestland, Quercus forestland, shrubland, wasteland, farmland, and roads. The results led to the conclusion that the method of taking different parameters in forestland and non-forestland segmentation was better than the same. The classification results indicate that, among the three classifiers, SVM has the best performance in classifying the natural forest of the Loess Plateau. With additional details and further validation, an approach based on more classifiers and different remote sensing resource will help improve the accuracy of forest classification.

Acknowledgements: We gratefully acknowledge the financial support of the National Natural Science Foundation of China (No. 30972296). We also thank the Huanglongshan Forestry Bureau for providing the data on the forest resource survey.

\section{REFERENCES}

1. Hansen MC, Townshend JRG, Sohlberg R, Defries RS (2000) Global land cover classification at $1 \mathrm{~km}$ spatial resolution using a classification tree approach. Int J Rem Sens 21, 1331-64.

2. Bonan GB (2008) Forests and climate change: Forcings, feedbacks, and the climate benefits of forests. Science 320, 1444-9.

3. Wulder MA, Kurz WA, Gillis M (2004) National level forest monitoring and modeling in Canada. Progr Plann 61, 365-81.

4. Treitz P, Howarth P (2000) High spatial resolution remote sensing data for forest ecosystem classification: an examination of spatial scale. Rem Sens Environ 72, 268-89.

5. Songmuang R, Charusiri P, Choowong M, Won-In K, Takashima I, Kosuwan S (2007) Detecting active faults using remote-sensing technique: A case study in the Sri Sawat Area, Western Thailand. Sci Asia 33, 23-33.

6. Huang MX, Gong JH, Shi Z, Liu C, Zhang LH (2007) Genetic algorithm-based decision tree classifier for remote sensing mapping with SPOT-5 data in the
HongShiMao watershed of the loess plateau, China. Neural Comput Appl 16, 513-7.

7. Rustomji P, Zhang XP, Hairsine PB, Zhang L, Zhao $\mathrm{J}$ (2008) River sediment load and concentration responses to changes in hydrology and catchment management in the Loess Plateau region of China. Water Resour Res 44, W00A04.

8. Ostwald M, Chen DL (2006) Land use change: Impacts of climate variations and policies among smallscale farmers in the Loess Plateau, China. Land Use Pol 23, 361-71.

9. Chen LD, Wang J, Fu BJ, Qiu Y (2001) Land use change in a small catchment of northern Loess Plateau, China. Agr Ecosyst Environ 86, 163-72.

10. Yongmei L, Guoan T, Tianwen L, Qinke Y (2003) An applied research on remote sensing classification in the Loess Plateau. J Geogr Sci 13, 395-9.

11. van Lier OR, Fournier RA, Bradley RL, Thiffault N (2009) A multi-resolution satellite imagery approach for large area mapping of ericaceous shrubs in Northern Quebec, Canada. Int J Appl Earth Obs Geoinform 11, 334-43.

12. Van Coillie FMB, Verbeke LPC, De Wulf RR (2007) Feature selection by genetic algorithms in objectbased classification of IKONOS imagery for forest mapping in Flanders, Belgium. Rem Sens Environ 110, 476-87.

13. Chubey MS, Franklin SE, Wulder MA (2006) Objectbased analysis of Ikonos-2 imagery for extraction of forest inventory parameters. Photogramm Eng Rem Sens 72, 383-94.

14. Mallinis G, Koutsias N, Tsakiri-Strati M, Karteris M (2008) Object-based classification using Quickbird imagery for delineating forest vegetation polygons in a Mediterranean test site. ISPRS J Photogramm Rem Sens 63, 237-50.

15. Haralick RM, Shapiro LG (1985) Image segmentation techniques. Comput Vis Graph Image Process 29, 100-32.

16. Franklin SE, Hall RJ, Moskal LM, Maudie AJ, Lavigne MB (2000) Incorporating texture into classification of forest species composition from airborne multispectral images. Int $J$ Rem Sens 21, 61-79.

17. Benz UC, Hofmann P, Willhauck G, Lingenfelder I, Heynen M (2004) Multi-resolution, object-oriented fuzzy analysis of remote sensing data for GIS-ready information. ISPRS J Photogramm Rem Sens 58, 239-58.

18. Mathieu R, Aryal J, Chong AK (2007) Object-based classification of IKONOS imagery for mapping largescale vegetation communities in urban areas. Sensors 7, 2860-80.

19. Ouma YO, Josaphat SS, Tateishi R (2008) Multiscale remote sensing data segmentation and postsegmentation change detection based on logical modeling: Theoretical exposition and experimental results for forestland cover change analysis. Comput 
Geosci 34, 715-37.

20. Thomas N, Hendrix C, Congalton RG (2003) A comparison of urban mapping methods using highresolution digital imagery. Photogramm Eng Rem Sens 69, 963-72.

21. Zhang XL, Feng XZ, Xiao PF (2015) Multi-scale segmentation of high spatial resolution remote sensing images using adaptively increased scale parameter. Photogramm Eng Rem Sens 81, 461-70.

22. Mitra P, Shankar BU, Pal SK (2004) Segmentation of multispectral remote sensing images using active support vector machines. Pattern Recogn Lett 25, 1067-74.

23. Laliberte AS, Rango A, Havstad KM, Paris JF, Beck RF, McNeely R, Gonzalez AL (2004) Object-oriented image analysis for mapping shrub encroachment from 1937 to 2003 in southern New Mexico. Rem Sens Environ 93, 198-210.

24. Balaguer A, Ruiz LA, Hermosilla T, Recio JA (2012) Definition of a comprehensive set of texture semivariogram features and their evaluation for objectoriented image classification. Comput Geosci 36, 231-40.

25. Li Y, Cheng B (2009) An improved $k$-nearest neighbor algorithm and its application to high resolution remote sensing image classification. In: 17th International Conference on Geoinformatics, Fairfax, VA.

26. Melgani F, Bruzzone L (2004) Classification of hyperspectral remote sensing images with support vector machines. IEEE Trans Geosci Rem Sens 42, 1778-90.

27. Petropoulos GP, Arvanitis K, Sigrimis N (2012) Hyperion hyperspectral imagery analysis combined with machine learning classifiers for land use/cover mapping. Expert Syst Appl 39, 3800-9.

28. Okubo S, Parikesit Muhamad D, Harashina K, Takeuchi K, Umezaki M (2010) Land use/cover classification of a complex agricultural landscape using single-dated very high spatial resolution satellitesensed imagery. Can J Rem Sens 36, 722-36.

29. Zhang XY, Feng XZ, Jiang H (2010) Object-oriented method for urban vegetation mapping using IKONOS imagery. Int J Rem Sens 31, 177-96. 